\title{
Intestinal Vascular Endothelial Growth Factor Is Decreased in Necrotizing Enterocolitis
}

\author{
Animesh Sabnis $^{a}$ Rosa Carrasco ${ }^{a}$ Shirley X.L. Liu ${ }^{a} \quad$ Xiaocai Yan $^{a}$ \\ Elizabeth Managlia $^{a}$ Pauline M. Chou ${ }^{c} \quad$ Xiao-Di Tan ${ }^{b, c} \quad$ Isabelle G. De Plaen ${ }^{a}$ \\ Divisions of a Neonatology and ${ }^{b}$ Gastroenterology, Department of Pediatrics, and ${ }^{c}$ Department of Pathology, \\ Ann and Robert H. Lurie Children's Hospital of Chicago, Northwestern University, Feinberg School of Medicine, \\ Chicago, III., USA
}

\section{Key Words}

Necrotizing enterocolitis · Animal model · Animal .

Vascular endothelial growth factor $A \cdot$ Human

\begin{abstract}
Background: Decreased intestinal perfusion may contribute to the development of necrotizing enterocolitis (NEC). Vascular endothelial growth factor (VEGF) is an angiogenic protein necessary for the development and maintenance of capillary networks. Whether VEGF is dysregulated in NEC remains unknown. Objectives: The objective of this study was to determine whether intestinal VEGF expression is altered in a neonatal mouse model of NEC and in human NEC patients. Methods: We first assessed changes of intestinal VEGF mRNA and protein in a neonatal mouse NEC model before significant injury occurs. We then examined whether exposure to formula feeding, bacterial inoculation, cold stress and/or intermittent hypoxia affected intestinal VEGF expression. Last, we visualized VEGF protein in intestinal tissues of murine and human NEC and control cases by immunohistochemistry. Results: Intestinal VEGF protein and mRNA were significantly decreased in pups exposed to the NEC protocol compared to controls. Hypoxia, cold stress and commensal bacteria, when administered together, significantly down-
\end{abstract}

regulated intestinal VEGF expression, while they had no significant effect when given alone. VEGF was localized to a few single intestinal epithelial cells and some cells of the lamina propria and myenteric plexus. VEGF staining was decreased in murine and human NEC intestines when compared to control tissues. Conclusion: Intestinal VEGF protein is reduced in human and experimental NEC. Decreased VEGF production might contribute to NEC pathogenesis.

(c) 2015 S. Karger AG, Basel

\section{Introduction}

Despite improvements in the survival of premature infants over the last several decades, advances in the treatment of necrotizing enterocolitis (NEC) have not been realized [1]. Indeed, the pathogenesis of NEC is incompletely understood and may be mediated by insufficient blood supply to the intestinal tissue [2].

Vascular endothelial growth factor (VEGF) A controls microvascular development through potent angiogenic, mitogenic and vascular permeability-enhancing activities [3] and may play an important role in the neonatal intestine. Human and mouse milk, which are known to protect against NEC, contain VEGF $[4,5]$. Low-birth-weight in-

\section{KARGER 125}

(c) 2015 S. Karger AG, Base

$1661-7800 / 15 / 1073-0191 \$ 39.50 / 0$

E-Mail karger@karger.com

www.karger.com/neo
Dr. Isabelle G. De Plaen

Department of Pediatrics/Neonatology, Ann and Robert H. Lurie Children's Hospital of Chicago, Northwestern University, Feinberg School of Medicine

225 E. Chicago Ave, Box 45, Chicago, IL 60611-2605 (USA)

E-Mail isabelledp@ northwestern.edu 
fants with polymorphisms associated with decreased VEGF production are more susceptible to NEC [6]. Finally, infants of mothers with preeclampsia, who are at increased risk for NEC [7], have impaired VEGF signaling and decreased fetal free VEGF [8]. Intestinal blood flow has been shown to be impaired in experimental models of NEC $[9,10]$. However, the role of VEGF in the development of NEC remains unclear.

We hypothesized that intestinal VEGF is downregulated in the intestine of premature infants at risk for NEC and that decreased VEGF production may contribute to the pathogenesis of the disease. In this study, using a neonatal mouse model established in our lab, we determined whether intestinal VEGF gene and protein expression is altered in pups exposed to the NEC protocol before significant injury occurs [11]. We further examined the effect of isolated NEC protocol stressors on intestinal VEGF gene expression. To correlate our findings to human NEC, we examined mucosal VEGF in murine and human NEC tissues and compared it to controls.

\section{Methods}

\section{Human Small Intestinal Tissue Collection}

Small intestinal surgical specimens of NEC patients $(n=7)$ and controls $(n=6$; ileal atresia, intestinal reanastomosis, duplication cyst or isolated perforation), all infants under 4 months of age (online suppl. table 1, see www.karger.com/doi/10.1159/000368879), were fixed in $10 \%$ formalin and paraffin embedded. Four-micrometer sections were obtained and immunostained for VEGF. Tissue collection was approved by the Lurie Children's Hospital of Chicago Institutional Review Board.

\section{Neonatal Mouse Model of NEC}

Animal studies were approved by the Stanley Manne Children's Research Institute Institutional Animal Care and Use Committee. Neonatal pups were separated from C57BL/6 dams within $12 \mathrm{~h}$ of birth and submitted to our NEC protocol as previously described [12]. The protocol consisted of orogastric inoculation with $10^{7}$ colony-forming units of standardized adult mouse commensal bacteria (fecal content), exposure to brief episodes of hypoxia (60 $\mathrm{s}$ in $100 \% \mathrm{~N}_{2}$ ) followed immediately by cold stress $\left(10 \mathrm{~min}\right.$ at $\left.4^{\circ} \mathrm{C}\right)$ twice daily and formula feeding every $3 \mathrm{~h} \mathrm{[12].}$ Pups were euthanized at various time points up to $72 \mathrm{~h}$. One group of pups was stressed for $24 \mathrm{~h}$ and returned to the dam and dam fed (DF) for an additional $24 \mathrm{~h}$ before tissue collection. Following euthanasia, collected intestines were flash frozen in liquid nitrogen or formalin fixed.

Friable neonatal intestines were not routinely transected and washed to avoid compromising protein integrity. In some experiments, to eliminate ingested VEGF, collected intestines were cut longitudinally on ice under a microscope and washed with ice-cold saline (containing 0.4 mM PMSF, $1 \mathrm{mM}$ DTT) to remove luminal contents.
To determine the contribution of each factor of our NEC model toward intestinal VEGF expression, DF neonatal mice were exposed to the stressors described above either alone or in combinations. Another group was separated from the dams within $12 \mathrm{~h}$ of birth and formula fed every $3 \mathrm{~h}$. Pups were euthanized after $24 \mathrm{~h}$, and their intestines were collected. A group of mice was exposed to hyperoxia $\left(100 \% \mathrm{O}_{2}, 2 \mathrm{~h}\right)$, which is known to downregulate VEGF in the lung [13], prior to euthanasia and intestinal tissue collection.

To examine the role of antenatal inflammation, given the association between chorioamnionitis and NEC [14], intestines from DF pups of pregnant mice injected with either $100 \mu \mathrm{g} / \mathrm{kg}$ of lipopolysaccharide (LPS) or normal saline intraperitoneally on day 17 of pregnancy were collected on day 1 .

\section{Immunohistochemistry}

To localize VEGF in mouse and human intestinal tissues, immunohistochemistry on formalin-fixed paraffin-embedded slides was performed using rabbit anti-VEGF monoclonal antibody (Abcam, Cambridge, Mass., USA). In mouse tissues, VEGF-positive cells were quantified in three randomly chosen $40 \times$ fields to generate an average per sample ( $\mathrm{n}=5$ samples per group). In human tissues, VEGF-positive cells and total number of cells in the lamina propria (LP) and epithelial layer were quantified in three randomly selected average-length villi within three randomly selected $40 \times$ fields by investigators (S.X.L.L. and X.Y.) blinded to the groups. The percentages of VEGF-positive cells were calculated.

\section{Western Blot}

To measure intestinal VEGF protein, whole neonatal mouse intestines were homogenized on ice and tissue lysates processed for Western blot analysis with anti-VEGF antibody (SC Biotechnology, Santa Cruz, Calif., USA) using a previously described protocol [15]. Results were expressed as VEGF/ $\beta$-actin band density ratio.

\section{Real-Time RT-PCR}

To measure intestinal VEGF mRNA, neonatal mouse intestines were preserved in RNALater (Qiagen, Valencia, Calif., USA). After tissue homogenization over ice, total RNA was purified using a Qiagen RNeasy Kit, and real-time RT-PCR was performed as previously described [15] using the following primers: VEGF164 (VEGF-A) forward, 5'-GCA GGC TGC TGT AAC GAT GA-3'; VEGF reverse, $5^{\prime}$-GCA TGA TCT GCA TGG TGA TGT T-3'; GAPDH forward, 5'-CTT CAC CAC CAT GGA GAA GGC-3'; GAPDH reverse, $5^{\prime}$-GGC ATG GAC TGT GGT CAT GAG- ${ }^{\prime}$. VEGF gene expression was normalized to GAPDH $(\triangle \mathrm{CT}=$ GAPDH - VEGF) as internal control. All samples were run in duplicate. Nontemplate controls were run in parallel and their fluorescence did not cross the threshold. There was a single product on melting curve analysis for VEGF and GAPDH.

\section{Statistical Analysis}

Two-sided Student $t$ test was performed for the comparison of two groups, and one-way analysis of variance (ANOVA) for multiple-group comparisons. For immunohistochemistry and Western blot analysis, data were expressed as the mean \pm standard error of the mean (SEM) and, for RT-PCR, as mean difference with confidence intervals (CI). Results were considered statistically significant when $\mathrm{p}$ value $<0.05$. 


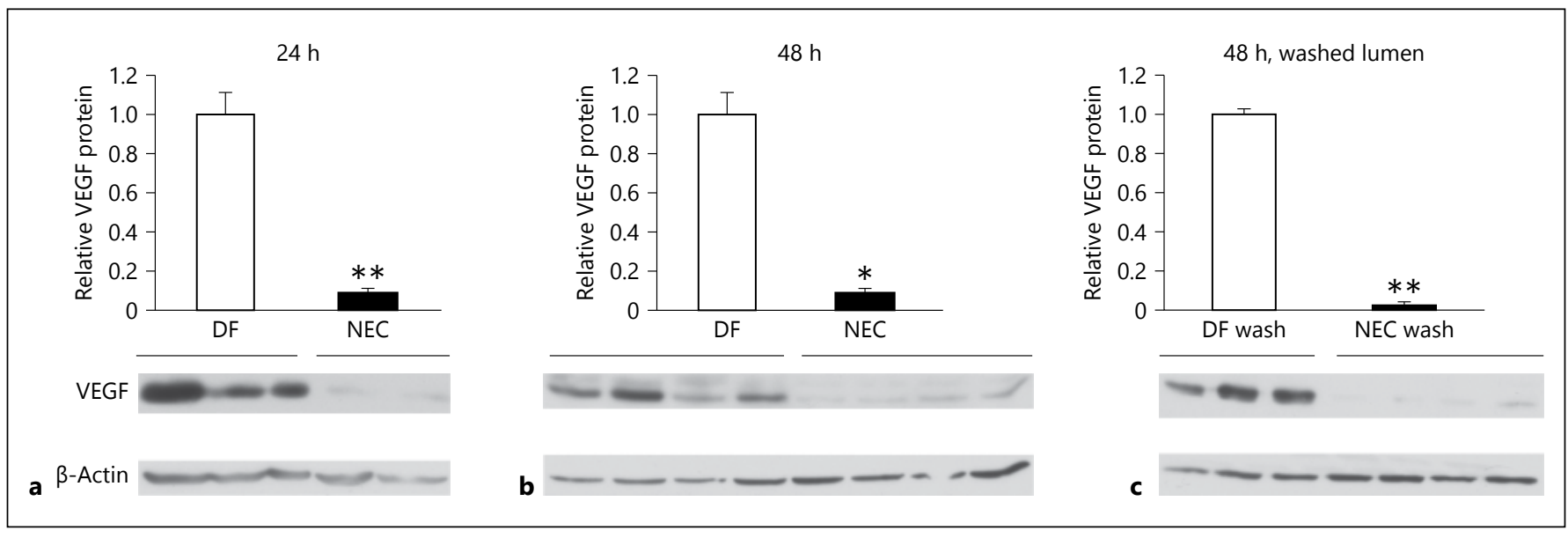

Fig. 1. Intestinal VEGF protein is reduced in experimental NEC. Newborn mice exposed to a NEC protocol or allowed to be DF were sacrificed at $24 \mathrm{~h}(\mathbf{a})$ or $48 \mathrm{~h}(\mathbf{b}, \mathbf{c})$ and intestines were col- lected for protein extraction. Relative VEGF protein measured by densitometry of Western blots (VEGF/ $\beta$-actin ratio) to DF controls. Mean values \pm SEM are presented. ${ }^{*} \mathrm{p}<0.05 ;{ }^{* *} \mathrm{p}<0.001$.

\section{Results}

\section{Intestinal VEGF Protein Is Decreased in a Neonatal} Mouse NEC Model

To test the hypothesis that VEGF is decreased in NEC, neonatal mouse pups were exposed to our NEC protocol [12]. When examined by Western blot, intestinal VEGF was decreased in pups submitted to the NEC protocol for $24 \mathrm{~h}(\mathrm{NEC} / \mathrm{DF}=0.08 \pm 0.03$ fold; $\mathrm{DF}, \mathrm{n}=15 ; \mathrm{NEC}, \mathrm{n}=6$; $\mathrm{p}<0.001)$ and $48 \mathrm{~h}(\mathrm{NEC} / \mathrm{DF}=0.10 \pm 0.04$ fold; $\mathrm{n}=4$ per group; $\mathrm{p}<0.05)$ when compared to their age-matched $\mathrm{DF}$ controls (fig. 1a, b).

To remove breast milk, which is known to contain VEGF [4], intestinal lumens were washed prior to protein extraction and Western blot analysis. In washed intestines, we observed a similar reduction in intestinal VEGF in stressed pups compared to DF controls $(\mathrm{NEC} / \mathrm{DF}=$ $0.02 \pm 0.01$ fold; $D F, n=3$; NEC, $n=4 ; p<0.001$; fig. 1c). To further confirm that this difference in intestinal VEGF reflects VEGF tissue changes, VEGF was localized by immunohistochemistry (fig. 2).

\section{Intestinal VEGF mRNA Is Decreased in Experimental NEC}

To examine whether the decrease in intestinal VEGF protein is due to a decrease in VEGF gene expression, we assessed intestinal VEGF mRNA by real-time RT-PCR. At $24 \mathrm{~h}$, when intestinal injury is rarely detected [11], we found that intestinal VEGF mRNA expression was significantly downregulated in stressed pups compared to controls (mean difference: 0.31 , CI $0.01-0.6$; $p<0.001$; fig. 3a), suggesting that the differences in intestinal VEGF protein result at least in part from a decrease in gene expression. VEGF expression remained low at 48 and $72 \mathrm{~h}$ (results not shown). When pups exposed to the NEC protocol for $24 \mathrm{~h}$ were returned to dams to be DF for another $24 \mathrm{~h}$, VEGF expression recovered to levels similar to controls (mean difference compared to pups stressed for $48 \mathrm{~h}:-0.5$, CI -0.9 to $-0.2 ; \mathrm{p}<0.01$; fig. $3 \mathrm{~b}$ ).

\section{Intestinal VEGF Is Decreased in Association with \\ Experimental Stressors That Cause NEC}

To determine which neonatal stressors affect VEGF expression in our experimental NEC model, DF pups were exposed to cold stress, hypoxia or adult commensal bacteria, alone or in combination, or to hyperoxia alone as a positive control. Another group was formula fed only. We found that exposure to either formula feeding (mean difference: $0.05, \mathrm{CI}-0.3$ to 0.4 ; not significant), cold stress (mean difference: $0.16, \mathrm{CI}-0.2$ to 0.6 ; not significant), hypoxia (mean difference: $0.04, \mathrm{CI}-0.4$ to 0.4 ; not significant), or adult commensal bacteria alone (mean difference: 0.16 , CI -0.3 to 0.6 ; not significant) was not significantly associated with changes in VEGF expression (fig. 4a). VEGF was significantly downregulated when DF mice were exposed to bacteria inoculation, cold stress and hypoxia together (mean difference: 0.54, CI $0.13-0.9 ; \mathrm{p}<$ 0.01 ), and when exposed to hyperoxia alone (mean difference: 0.53 , CI $0.13-0.94 ; \mathrm{p}<0.01$; fig. $4 \mathrm{a}$ ). Antenatal maternal LPS injection caused a decrease in intestinal VEGF expression in the pups compared to controls (mean difference: 0.32 , CI $0.19-0.45 ; \mathrm{p}<0.001$; fig. $4 \mathrm{~b}$ ). 

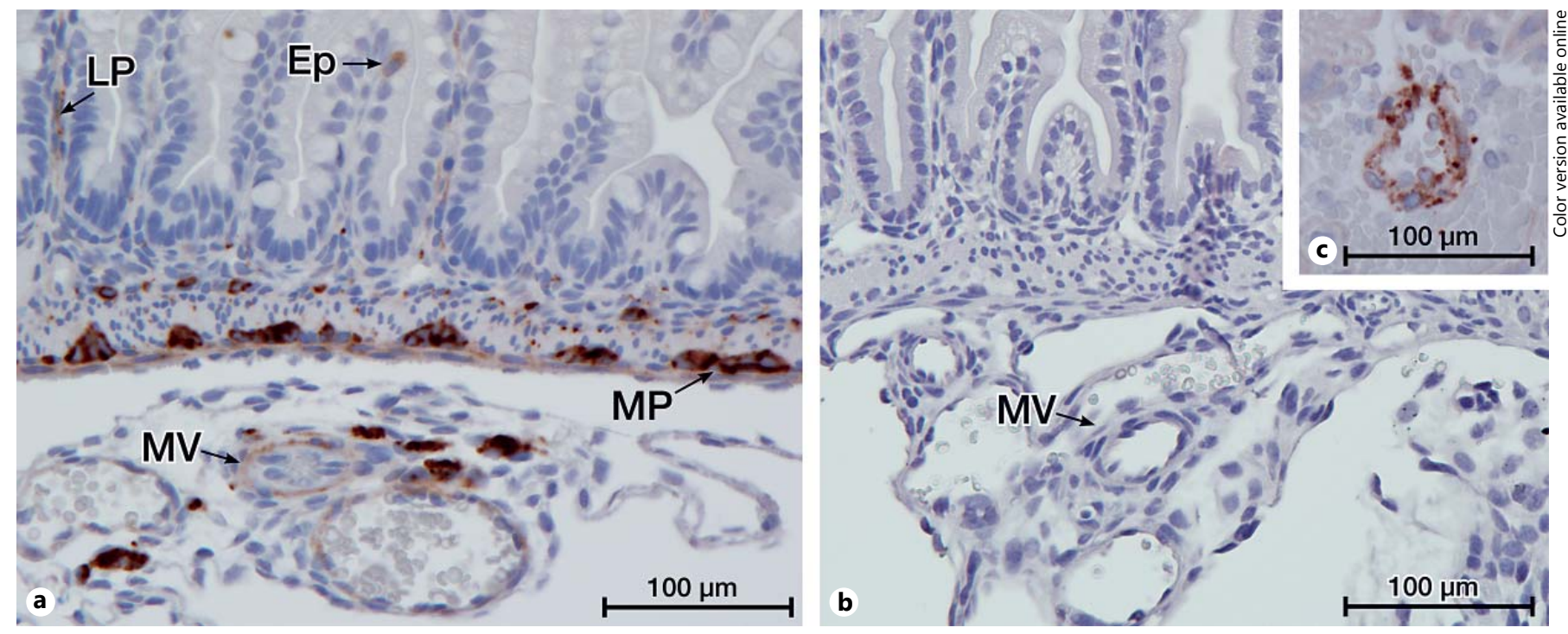

Fig. 2. VEGF localizes to cells of the intestinal epithelium, the lamina propria and the myenteric plexus in the neonatal mouse small intestine. The small intestines of day-1 DF pups were immunostained for VEGF. a Positive staining shown in mesenteric vessels as well as in the LP, myenteric plexus and few single cells of the epithe- lium. b The specificity of VEGF staining was confirmed by positive staining of mouse placental vascular cells (c, positive control) and by the absence of staining in intestinal tissues when the primary antibody was omitted ( $\mathbf{b}$, negative control). LP = Lamina propria; Ep = epithelium; $\mathrm{MP}=$ myenteric plexus; $\mathrm{MV}=$ mesenteric vessels.
Fig. 3. Intestinal VEGF mRNA expression is downregulated in a neonatal mouse model of NEC. a Pups exposed to the NEC protocol for $24 \mathrm{~h}(\mathrm{n}=9)$ and DF controls $(\mathrm{n}=7)$ were sacrificed and their intestines collected. VEGF mRNA expression was measured by real-time RT-PCR, normalized to GAPDH and expressed as fold-expression relative to DF controls. b Pups exposed to the NEC protocol for $24 \mathrm{~h}$ were returned to the dams for $24 \mathrm{~h}$ prior to intestine collection. ${ }^{*} \mathrm{p}<0.01{ }^{* *} \mathrm{p}<0.001$.

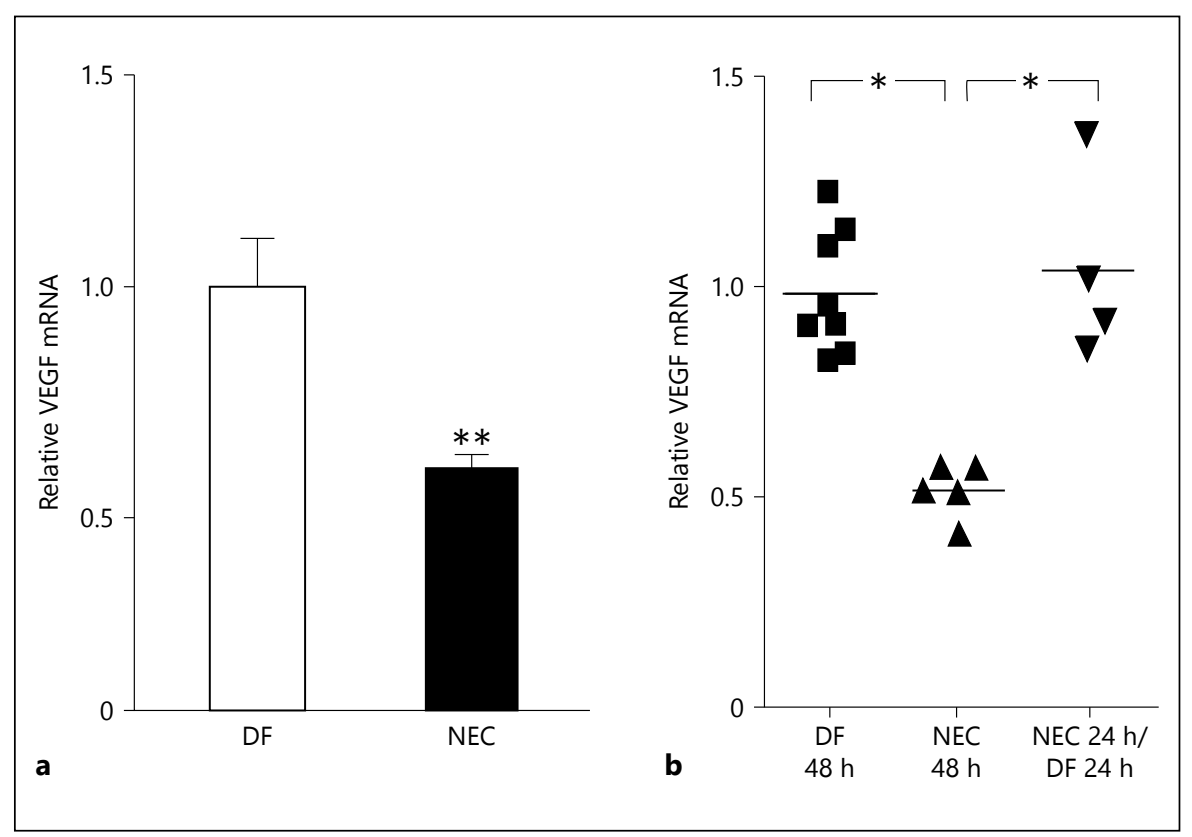

\section{Small Intestinal VEGF Staining Is Decreased in} Experimental NEC and in Human NEC Patients

When murine intestinal tissues were immunostained with a monoclonal antibody against VEGF, we found a significant reduction in VEGF-positive cells in the small intestinal LP of mice exposed to our NEC protocol for $24 \mathrm{~h}$ compared to DF controls ( $\mathrm{n}=5$ per group; DF $82.8 \pm$ 6.6 ; NEC $48.8 \pm 1.9 ; \mathrm{p}<0.005$; fig. 5). No significant injury is typically detected by $24 \mathrm{~h}$ in our model [11]. In intestinal tissues obtained from human subjects (online 


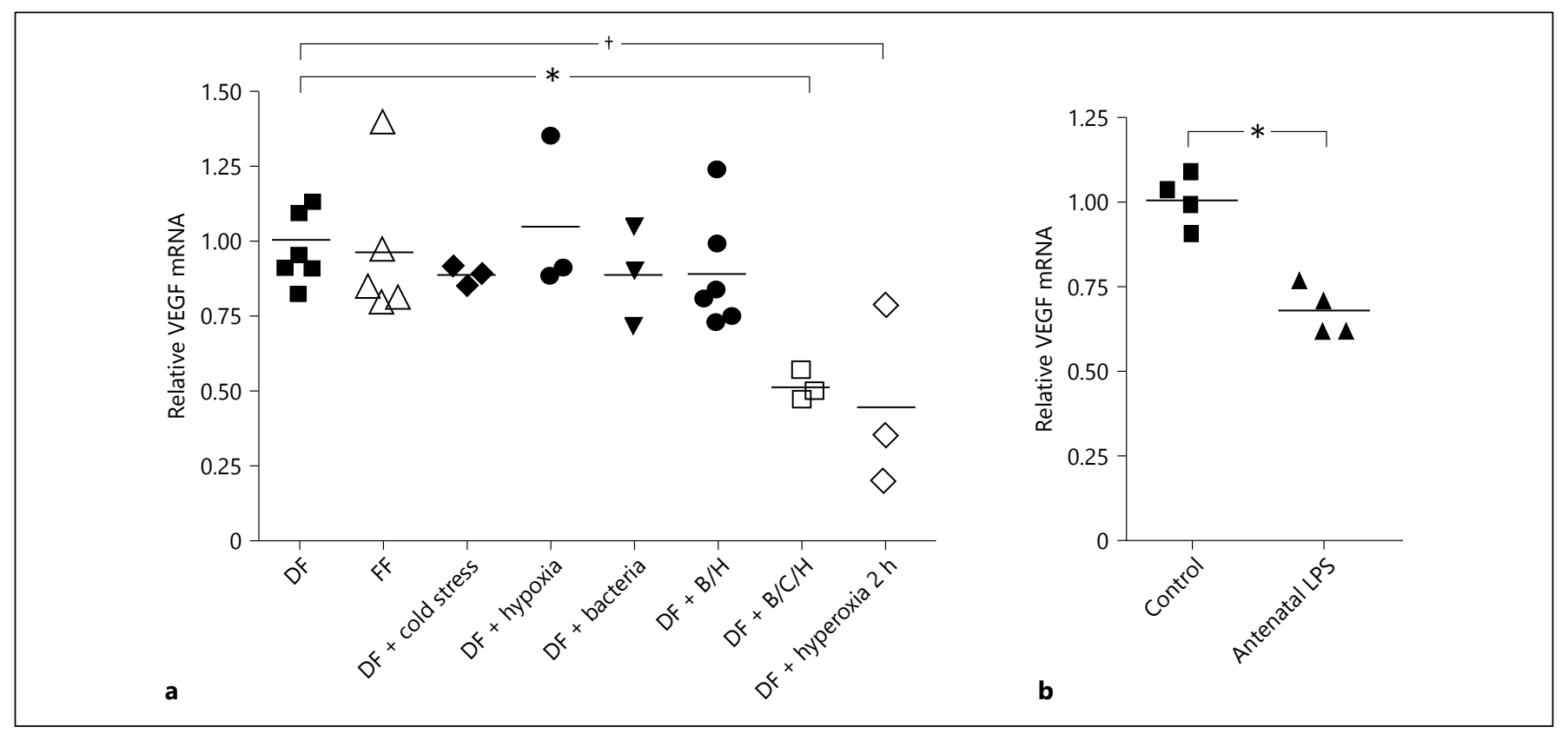

Fig. 4. Commensal bacteria, cold stress and hypoxia administered together, and exposure to antenatal inflammation alone, downregulate VEGF mRNA expression in the intestine of neonatal mice. a DF or formula-fed pups were submitted for $24 \mathrm{~h}$ to cold stress, hypoxia or commensal bacteria exposure alone or in combinations. DF mice submitted to hyperoxia alone for $2 \mathrm{~h}$ were used as positive control. VEGF mRNA expression was measured by re- al-time RT-PCR, normalized to GAPDH and expressed as foldexpression relative to age-matched DF controls $\left({ }^{*} \mathrm{p}<0.05{ }^{\dagger} \mathrm{p}<\right.$ $0.01)$. b Intestinal VEGF expression was reduced in 24-hour DF pups exposed to antenatal inflammation by prenatal LPS treatment of the dam compared to controls $(* \mathrm{p}<0.001)$. FF $=$ Formula fed; $\mathrm{B} / \mathrm{H}=$ bacteria and hypoxia; $\mathrm{B} / \mathrm{C} / \mathrm{H}=$ bacteria, cold stress and hypoxia. suppl. table 1), we found a lower percentage of VEGFpositive cells in NEC patients $(n=7)$ when compared to control samples $(n=6)$ overall, as well as fewer VEGFpositive cells in the LP and epithelial cell layers specifically (overall percentage of VEGF-positive cells: control $21 \pm 1$; NEC $10 \pm 1 ; \mathrm{p}<0.0001$; percentage of VEGF-positive LP cells: control $52 \pm 3$; NEC $23 \pm 1 ; \mathrm{p}=0.0001$; percentage of VEGF-positive epithelial cells: control $36 \pm 2$; NEC $17 \pm 2 ; \mathrm{p}<0.0001$; fig. 6 ). Healthy areas beyond the necrotic zones were selected for VEGF quantification in order to avoid the possibility that VEGF protein detection would be hampered by intestinal tissue degradation.

\section{Discussion}

The intestinal circulation has long been suspected to contribute to the pathogenesis of NEC $[9,16]$. Evidence that alterations in intestinal microvascular blood flow may play a role in NEC has been found in both animals $[9,10]$ and human subjects [17]. Although VEGF signaling is impaired in several diseases that uniquely affect ne- onates, as well as in animal models of those conditions [18-20], whether VEGF expression is altered in the intestine in NEC remains unknown. A pilot study showed that VEGF protein is decreased in a neonatal mouse NEC model [unpublished data: Carrasco et al: Federation of American Societies for Experimental Biology, Anaheim, CA, 2010. Abstract No. 1007.3], and this finding was confirmed in neonatal rats exposed for 3 days to formula feeding, $100 \% \mathrm{CO}_{2}$, cold stress and hyperoxia [21]. In this study, we further examined the role of perinatal stressors in NEC and how VEGF is affected in human NEC.

Here, we show that VEGF protein is decreased in small intestine specimens resected from premature neonates with NEC. To determine whether the decrease in VEGF expression occurs prior to intestinal injury, pups were submitted to our NEC protocol for $24 \mathrm{~h}$, before intestinal injury is commonly seen, and compared to DF controls [11]. We found that VEGF protein assessed by Western blot was strongly decreased in stressed pups, due at least in part to downregulation of VEGF gene expression. Furthermore, we found that while exposure to stressors individually did not significantly change intestinal VEGF 


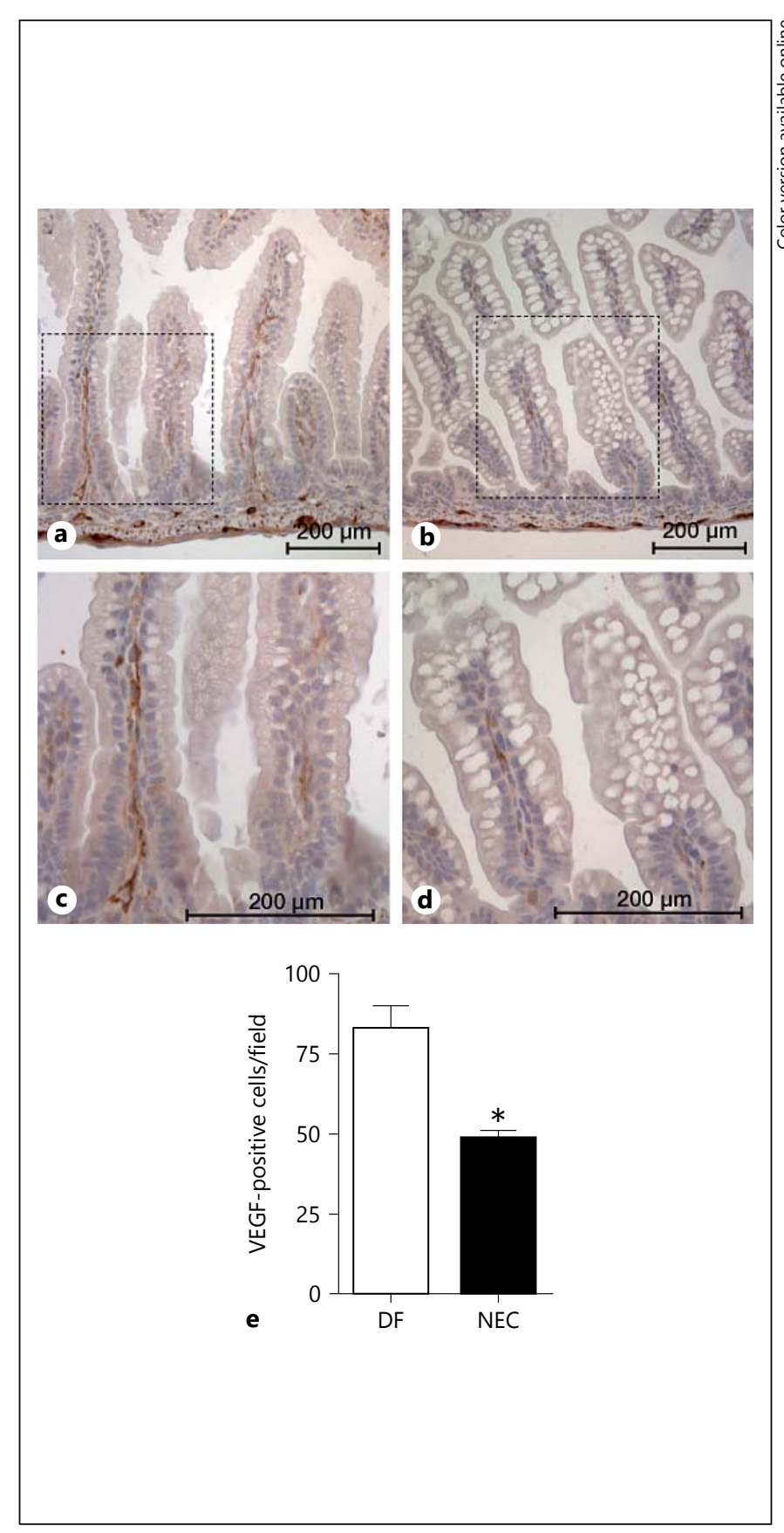

Fig. 5. VEGF staining is decreased in intestinal tissues of mice submitted to a NEC protocol. After immunostaining tissues for VEGF, we found significantly fewer VEGF-positive cells in the small intestinal LP of mice exposed to our NEC protocol (b, enlarged in $\mathbf{d}$ ) compared to DF controls (a, enlarged in c). Quantification of VEGF + cell per field $(\times 20$ magnification $) . \mathbf{e}^{*} \mathrm{p}<0.005$.

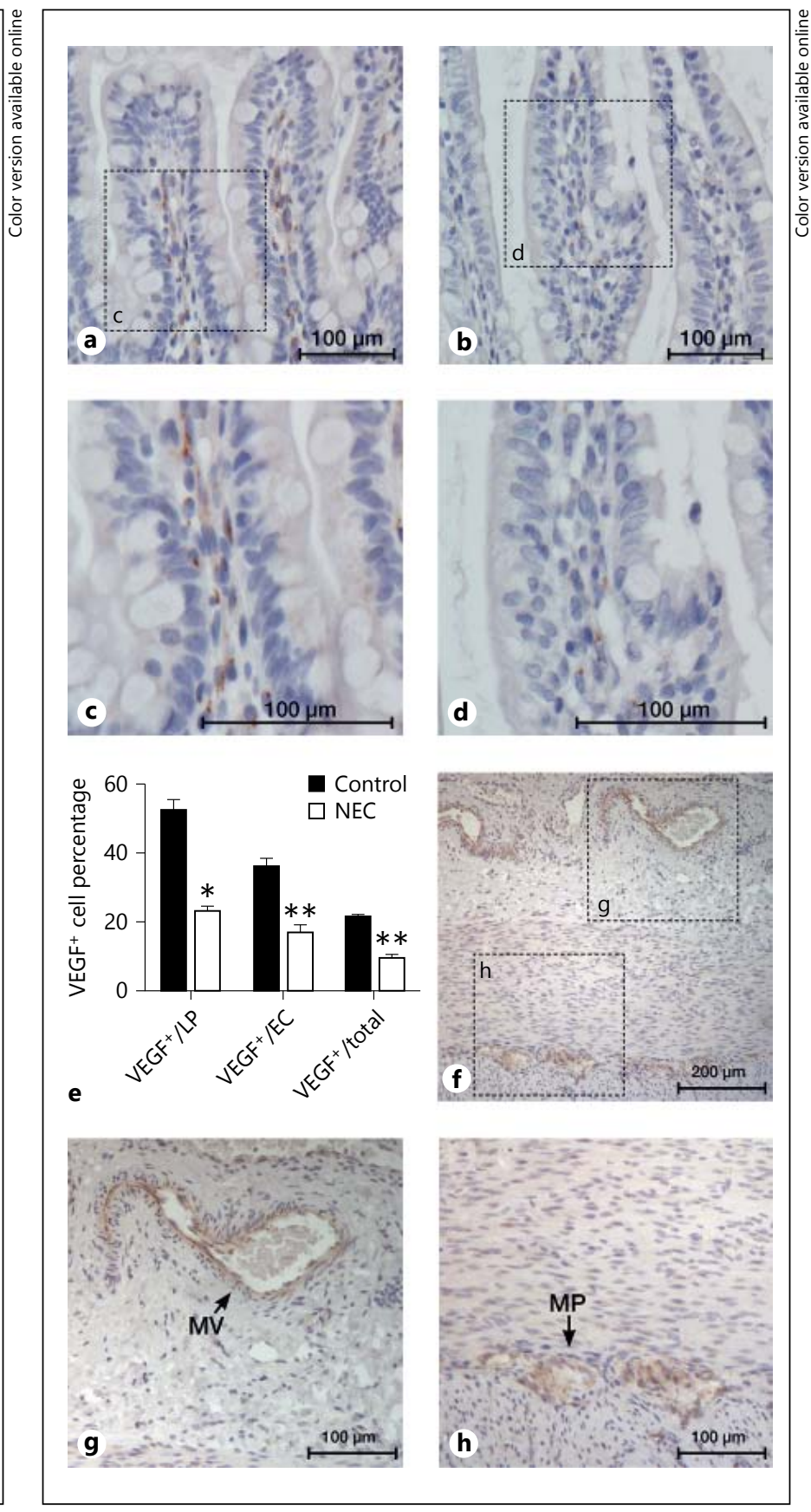

Fig. 6. VEGF staining is decreased in small intestinal tissues of human NEC patients. Immunohistochemical staining was performed on human small intestinal samples using VEGF antibody. Control cases (a, enlarged in c) showed VEGF-positive cells in the intestinal epithelial cell layer and the LP. We found significantly fewer VEGF-positive cells in small intestinal tissue samples resected from NEC patients (b, enlarged in d) compared to control samples (a). e $^{*} \mathrm{p}<0.005 ;{ }^{* *} \mathrm{p}<0.0001$. VEGF positive cell percentage in LP, EC and total cells of the villi. $\mathbf{f}$ The intestinal wall of a control case is shown here with enlarged areas $(\mathbf{g}, \mathbf{h})$ showing VEGF staining in mesenteric vessels and myenteric plexus. $\mathrm{EC}=$ Epithelial cell layer; $\mathrm{MV}=$ mesenteric vessels; $\mathrm{MP}=$ myenteric plexus. 
gene expression, bacterial inoculation, hypoxia and cold stress together significantly downregulated intestinal VEGF expression. Hyperoxia alone also downregulated intestinal VEGF expression, which is consistent with findings in other tissues [22]. Antenatal inflammation has been shown to be an independent risk factor for NEC [14]. Interestingly, we found that antenatal maternal exposure to LPS decreased VEGF expression in the intestine of 1-day-old mice. A limitation of our study is the absence of correlation between VEGF expression and NEC severity in either experimental or human samples.

The few studies that have localized VEGF in intestinal tissues have reported inconsistent findings across studies and species [23-26]. Ubiquitous VEGF staining has been noted in fetal sheep small intestines [23] and in human adult tissues affected by inflammatory bowel disease $[25,26]$. Conversely, a study of human neonatal small intestines has reported VEGF expression solely in endothelial cells [24]. These inconsistencies may result from the variable affinity and lack of specificity of the most commonly used VEGF primary antibodies [27]. In this study, using a monoclonal antibody, we have localized VEGF to specific cells in both human and mouse neonatal intestinal tissues, and we have shown that mucosal VEGF staining is decreased in both murine and human NEC.
In conclusion, we have shown that in the intestine of newborn mice exposed to a NEC protocol, intestinal VEGF mRNA and protein are decreased before significant histologic injury occurs. VEGF is present in both human and mouse neonatal intestinal tissues, and VEGF is decreased in the intestinal mucosa of mice exposed to a NEC protocol and human infants with surgical NEC. These findings suggest that VEGF downregulation may play a role in NEC. Additional studies aimed at modulating VEGF expression in our NEC model are needed to further elucidate the role of VEGF in NEC.

\section{Acknowledgements}

We thank Akihiro Asai and Kathryn Farrow for critical discussion and critique of this article. We thank Donna Kersey, Catherine Marek and Runlan Tian for their technical contributions. This work was supported by grants from the Ann and Robert H. Lurie Children's Hospital of Chicago Research Center (A.S.), the Thrasher Research Fund (R.C.) and NIH grants R01DK064240 (X.-D.T.) and R01HD060876 (I.G.D.).

\section{Disclosure Statement}

The authors have no conflicts of interest.

\section{References}

1 Fanaroff AA, Hack M, Walsh MC: The NICHD neonatal research network: changes in practice and outcomes during the first 15 years. Semin Perinatol 2003;27:281-287.

$>2$ De Plaen IG: Inflammatory signaling in necrotizing enterocolitis. Clin Perinatol 2013;40: 109-124.

-3 Gerber HP, Hillan KJ, Ryan AM, Kowalski J, Keller GA, Rangell L, Wright BD, Radtke F, Aguet M, Ferrara N: VEGF is required for growth and survival in neonatal mice. Development 1999;126:1149-1159.

-4 Siafakas CG, Anatolitou F, Fusunyan RD, Walker WA, Sanderson IR: Vascular endothelial growth factor (VEGF) is present in human breast milk and its receptor is present on intestinal epithelial cells. Pediatr Res 1999;45: 652-657.

5 Rossiter H, Barresi C, Ghannadan M, Gruber F, Mildner M, Fodinger D, Tschachler E: Inactivation of VEGF in mammary gland epithelium severely compromises mammary gland development and function. FASEB J 2007;21:3994-4004.

6 Banyasz I, Bokodi G, Vasarhelyi B, Treszl A, Derzbach L, Szabo A, Tulassay T, Vannay A:
Genetic polymorphisms for vascular endothelial growth factor in perinatal complications. Eur Cytokine Netw 2006;17:266-270.

7 Cetinkaya M, Ozkan H, Koksal N: Maternal preeclampsia is associated with increased risk of necrotizing enterocolitis in preterm infants. Early Hum Dev 2012;88:893-898.

-8 Maynard SE, Min JY, Merchan J, Lim KH, Li J, Mondal S, Libermann TA, Morgan JP, Sellke FW, Stillman IE, Epstein FH, Sukhatme VP, Karumanchi SA: Excess placental soluble fms-like tyrosine kinase 1 (sFlt1) may contribute to endothelial dysfunction, hypertension, and proteinuria in preeclampsia. J Clin Invest 2003;111:649-658.

-9 Downard CD, Grant SN, Matheson PJ, Guillaume AW, Debski R, Fallat ME, Garrison $\mathrm{RN}$ : Altered intestinal microcirculation is the critical event in the development of necrotizing enterocolitis. J Pediatr Surg 2011;46: 1023-1028.

10 Yu X, Radulescu A, Zorko N, Besner GE: Heparin-binding EGF-like growth factor increases intestinal microvascular blood flow in necrotizing enterocolitis. Gastroenterology 2009; 137:221-230.
11 Bergmann KR, Liu SX, Tian R, Kushnir A, Turner JR, Li HL, Chou PM, Weber CR, De Plaen IG: Bifidobacteria stabilize claudins at tight junctions and prevent intestinal barrier dysfunction in mouse necrotizing enterocolitis. Am J Pathol 2013;182:1595-1606.

12 Tian R, Liu SX, Williams C, Soltau TD, Dimmitt R, Zheng X, De Plaen IG: Characterization of a necrotizing enterocolitis model in newborn mice. Int J Clin Exp Med 2010;3: 293-302.

13 Hosford GE, Olson DM: Effects of hyperoxia on VEGF, its receptors, and HIF-2alpha in the newborn rat lung. Am J Physiol Lung Cell Mol Physiol 2003;285:L161-L168.

14 Been JV, Lievense S, Zimmermann LJ, Kramer BW, Wolfs TG: Chorioamnionitis as a risk factor for necrotizing enterocolitis: a systematic review and meta-analysis. J Pediatr 2013; 162:236-242.e2.

15 Liu SX, Tian R, Baskind H, Hsueh W, De Plaen IG: Platelet-activating factor induces the processing of nuclear factor-kappaB p105 into p50, which mediates acute bowel injury in mice. Am J Physiol Gastrointest Liver Physiol 2009;297:G76-G81. 
16 Nankervis CA, Giannone PJ, Reber KM: The neonatal intestinal vasculature: contributing factors to necrotizing enterocolitis. Semin Perinatol 2008;32:83-91.

17 Nowicki PT, Dunaway DJ, Nankervis CA, Giannone PJ, Reber KM, Hammond SB, Besner GE, Caniano DA: Endothelin-1 in human intestine resected for necrotizing enterocolitis. J Pediatr 2005;146:805-810.

18 Abman SH: Impaired vascular endothelial growth factor signaling in the pathogenesis of neonatal pulmonary vascular disease. Adv Exp Med Biol 2010;661:323-335.

19 Levesque BM, Kalish LA, Winston AB, Parad RB, Hernandez-Diaz S, Phillips M, Zolit A, Morey J, Gupta M, Mammoto A, Ingber DE, Van Marter LJ: Low urine vascular endothelial growth factor levels are associated with mechanical ventilation, bronchopulmonary dysplasia and retinopathy of prematurity. Neonatology 2013;104: $56-64$.
20 Tsao PN, Wei SC: Prenatal hypoxia downregulates the expression of pulmonary vascular endothelial growth factor and its receptors in fetal mice. Neonatology 2013;103:300-307.

21 Karatepe HO, Kilincaslan H, Berber M, Ozen A, Saricoban HE, Ustek D, Kemik AS, Adas M, Bakar F: The effect of vascular endothelial growth factor overexpression in experimental necrotizing enterocolitis. Pediatr Surg Int 2014;30:327-332.

22 Alon T, Hemo I, Itin A, Pe'er J, Stone J, Keshet E: Vascular endothelial growth factor acts as a survival factor for newly formed retinal vessels and has implications for retinopathy of prematurity. Nat Med 1995;1:1024-1028.

23 Holmes K, Charnock Jones SD, Forhead AJ, Giussani DA, Fowden AL, Licence D, Kempster S, Smith GC: Localization and control of expression of VEGF-A and the VEGFR-2 receptor in fetal sheep intestines. Pediatr Res 2008;63:143-148.
24 Vuorela P, Andersson S, Carpen O, Ylikorkala O, Halmesmaki E: Unbound vascular endothelial growth factor and its receptors in breast, human milk, and newborn intestine. Am J Clin Nutr 2000;72:1196-1201.

25 Tsiolakidou G, Koutroubakis IE, Tzardi M, Kouroumalis EA: Increased expression of VEGF and CD146 in patients with inflammatory bowel disease. Dig Liver Dis 2008;40:673679.

26 Frysz-Naglak D, Fryc B, Klimacka-Nawrot E, Mazurek U, Suchecka W, Kajor M, Kurek J, Stadnicki A: Expression, localization and systemic concentration of vascular endothelial growth factor (VEGF) and its receptors in patients with ulcerative colitis. Int Immunopharmacol 2011;11:220-225.

27 Van Der Loos CM, Meijer-Jorna LB, Broekmans ME, Ploegmakers HP, Teeling P, De Boer OJ, Van Der Wal AC: Anti-human vascular endothelial growth factor (VEGF) antibody selection for immunohistochemical staining of proliferating blood vessels. J Histochem Cytochem 2010;58:109-118. 